\title{
Notch Effects Under Ultrasonically Vibrating Stress*
}

\author{
Takahiko $\mathrm{KUNOH}^{* *}$, Ken TERAO**, \\ Shinji KASUGA** and Masao MIZUNO**
}

\begin{abstract}
In this study, stress concentration factors and fatigue strength reduction factors are obtained for the case of a round bar of mild steel with a V-groove under ultrasonically vibration stress. The stress concentration factors are determined by FEM analysis on the eigenmodes. The fatigue strength reduction factors are obtained by combining the above analysis and the results of the ultrasonic fatigue tests. These factors are determined under ultrasonically vibrating stress. These results could make the ultrasonic fatigue test more popular than the ordinary fatigue test.
\end{abstract}

Key Words: Fatigue, Material Testing, Ultrasonics, Stress Concentration Factor, Fatigue Strength Reduction Factor, Ultrasonic Fatigue Test, FEM

\section{Introduction}

In the ultrasonic fatigue test, the testpiece is vibrated longitudinally. By utilizing vibration stress in the resonant state of the specimen, a fatigue test is conducted. Contrary to the ordinary fatigue test, the ultrasonic fatigue test can be conducted within a short period of time. (In the case of $17 \mathrm{kHz}$, the time required for $10^{8}$-times repeated loading is about 100 min.) The test also attracts attention as an effective means for studying high-speed fatigue, and studies have been made from various standpoints. They include, for instance, studies on changes in mechanical properties due to ultrasonic fatigue ${ }^{(1)(2)}$, the fatigue limits $^{(4) \sim(6)}$, the effects of cooling water on corrosion ${ }^{(4)}$, the relation between ultrasonic fatigue and internal friction ${ }^{(3)(7)}$, and ultrasonic fatigue strength under mean stress $^{(8)}$. The stress concentration factor and fatigue strength reduction factor under ultrasonically vibrating stress are considered indispensable in

* Received 22nd March, 1988. Paper No. 87-0258 A

* Faculty of Science and Technology, Keio University, 3-14-1 Hiyoshi, Kohoku-ku, Yokohama, 223, Japan designing ultrasonic application equipment but, so far, no studies have been made on these factors. This is considered attributable to the fact that in terms of the principles of the ultrasonic fatigue test, measurements of force and stress are difficult. In the present study, therefore, an eigenmode analysis of the ultrasonic vibrating system and an ultrasonic fatigue test applied to a round bar testpiece of mild steel with a circular $\mathrm{V}$-groove were conducted. From the results of these tests, the stress concentration factor and fatigue strength reduction factor were obtained and the notch effect under ultrasonically vibrating stress was clarified.

\section{Object and Method of Analysis}

In general, the vibrating system for the ultrasonic fatigue test consists of a vibrator, cone, horn and testpiece. In the present study, however, to make matters simple, a system consisting of a testpiece and an adjoining horn is used as the object of analysis. An exponential horn for $17 \mathrm{kHz}$ made of titanium alloy (6 $\mathrm{Al} 4 \mathrm{~V}$ ) and a testpiece of a round bar with a circular $\mathrm{V}$-groove are shown in Table 1 and Figs. 1 and 2. These vibrating systems are subjected to an eigen- 
mode analysis by the finite element method (FEM). Further, by assuming that the horn is a part of the driving system, displacement amplitudes at the nodal points are normalized by the axial displacement amplitude at the center of the larger end surface of the horn.

The finite element model of the vibrating system and the finer mesh in the region of the $\mathrm{V}$-groove are

Table 1 Horn and Testpiece

\begin{tabular}{|l|l|l|}
\hline & \multicolumn{1}{|c|}{ Horn } & \multicolumn{1}{|c|}{ Testpiece } \\
\hline Material & Ti-Alloy $(6 \mathrm{Al} / \mathrm{VV})$ & $\mathrm{S} 10 \mathrm{C}$ \\
Density & $4.42 \times 10^{3} \mathrm{~kg} / \mathrm{m}^{3}$ & $7.86 \times 10^{3} \mathrm{~kg} / \mathrm{m}^{3}$ \\
Young's Modulus & $1.127 \times 10^{2} \mathrm{GPa}$ & $2.073 \times 10^{2} \mathrm{GPa}$ \\
Shear Moduls & $4.41 \times 10 \mathrm{GPa}$ & $8.23 \times 10^{\mathrm{GPa}}$ \\
\hline
\end{tabular}

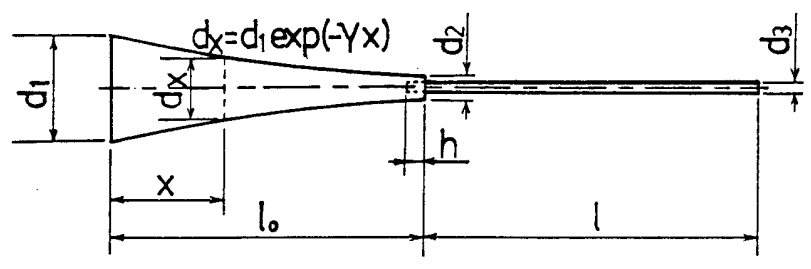

$d_{1}=56 \mathrm{~mm}, d_{2}=12 \mathrm{~mm}, d_{3}=6 \mathrm{~mm}, h=10 \mathrm{~mm}$ $l_{0}=165 \mathrm{~mm}, l=144 \mathrm{~mm}, \gamma=0.0093$

Fig. 1 Ultrasonically vibrating System


Detailed drawing of A

NOTCH RADIUS $p(\mathrm{~mm})$

\begin{tabular}{|c|c|c|c|c|}
\hline 0.2 & 0.4 & 0.8 & 1.2 & \\
\hline OTC1 & $\mathrm{TH}$ & (m & & \\
\hline 0.2 & 04 & 0.6 & 00 & 1.0 \\
\hline
\end{tabular}

Fig. 2 Shape of notched testpiece shown in Figs. 3 (a) $-(d)$. These elements are divided into triangular and square ring elements, and in the vicinity of the notch root surface, iso-parametric triangular ring elements are used to improve analytical accuracy.

The eigenmode analysis in the present study was conducted using the Integrated Structure Analysis System II (ISAS II) at the Calculation Center of Tokyo University.

\section{Notch Shape and Resonant Frequency for the System}

Figure 4 shows the relations among the notch depth, notch radius and resonant frequency obtained by the eigenmode analysis of the resonant frequency. It indicates that as the notch depth increases and as the notch radius increases, the resonant frequency of the system tends to decrease. In this study, however, the resonant frequency only changes within $0.1 \mathrm{kHz}$.

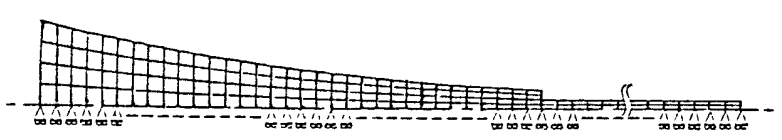

(a) Horn and testpiece

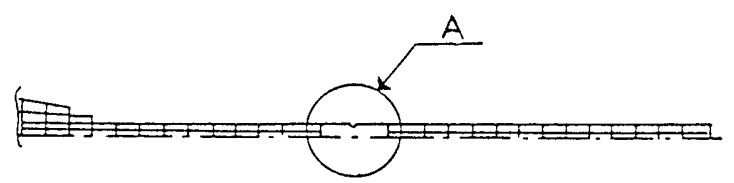

(b) Notched testpiece

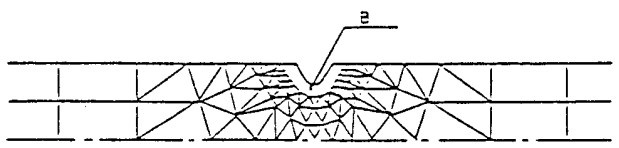

(c) Detailed drawing of $\mathrm{A}$

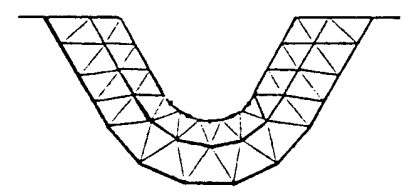

(d) Detailed drawing of B

Fig. 3 Finite element model of the ultrasonically vibrating system 


\section{Stress Concentration Factor Under Ultrasonically Vibrating Stress}

\subsection{Calculation method for the stress concentration factor}

When a static tensile load is applied to the circular $\mathrm{V}$-grooved round bar, the nominal stress of the notch section, namely, the mean stress, has a value obtained by dividing the load by the area of the cross section. In the case of ultrasonic vibration, however, measurements of the load are difficult and, thus, it is impossible to obtain the mean stress of the notch section, unlike under ordinary static load conditions. It is necessary, therefore, to obtain the mean stress of the notch section by calculation using the results of the eigenmode analysis as follows.

Figure 5 denotes the axial stress at the center of gravity of the triangular ring element on the notch section by $\sigma_{i}{ }^{*}$, and the radial sectional area of the element by $S_{i}$. The mean stress $\sigma^{*}$ mean of the notch section can then be obtained by the following equation:

$$
\sigma_{\text {mean }}^{*}=\frac{\sum \sigma_{i}^{*} S_{i}}{\sum S_{i}}=\frac{\sum \sigma_{i}^{*}\left(r_{i}^{2}-r_{i-1}^{2}\right)}{r^{2}}
$$

The relations among $\sigma^{*}$ mean, notch depth and

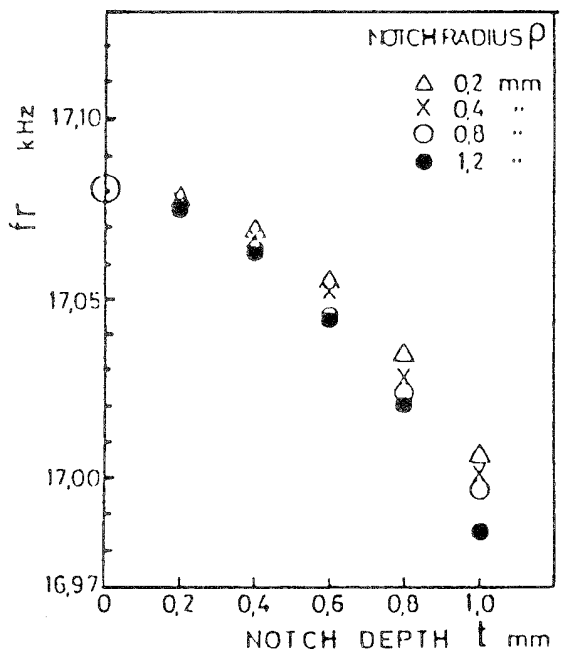

Fig. 4 The relation among the resonant frequency, $f_{r}$, notch depth, $t$, and notch radius, $o$

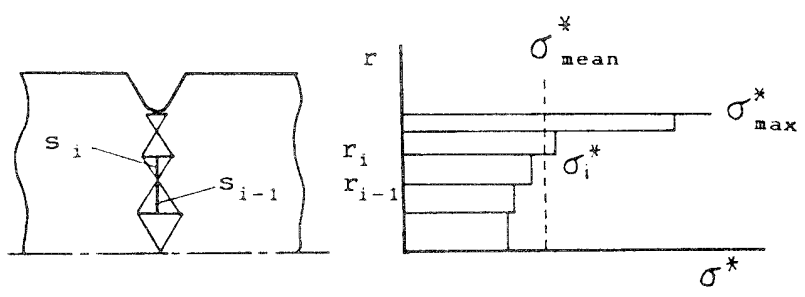

Fig. 5 Finite element mesh and distribution of the axial stress on the cross section of the notch region notch radius are shown in Fig. 6. Also, the maximum stress $\sigma_{\max }^{*}$ of the notch root obtained from the analysis is shown in Fig. 7 for various notch depths and radii.

Then the stress concentration factors, $\alpha_{m}$, under ultrasonically vibrating stress for each shape of the circular $\mathrm{V}$-groove can be obtained using the following equation:

$$
\alpha_{m}=\frac{\sigma_{\max }^{*}}{\sigma_{\text {mean }}^{*}}
$$

Namely, for a total of 20 shapes with notch depths, $\mathrm{t}$, of $0.2,0.4,0.6,0.8$ and $1.0 \mathrm{~mm}$ and notch radii, $\rho$, of $0.2,0.4,0.8$ and $1.0 \mathrm{~mm}$, the values of $\alpha_{m}$ under ultrasonically vibrating stress are obtained.

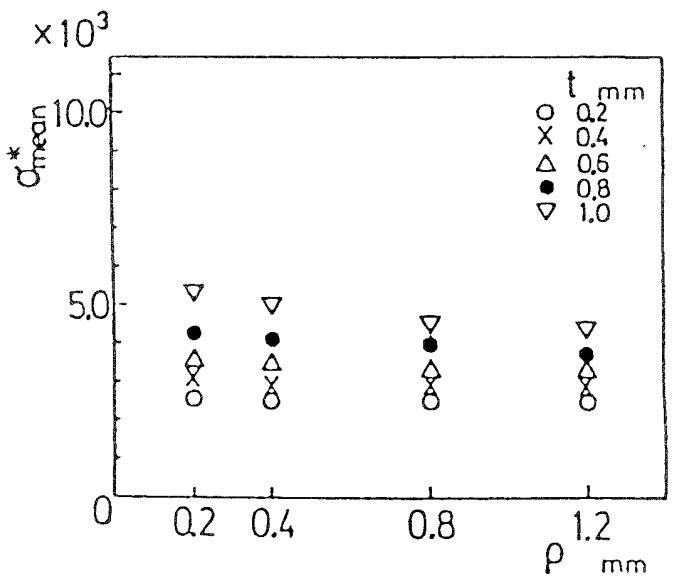

$\sigma_{\text {mean }}^{*}$ mean stress on the cross section of the notch bottom

$\rho:$ notch radius

$t:$ notch depth

Fig. 6 The relation among $\sigma^{*}$ mean, $\rho$ and $t$

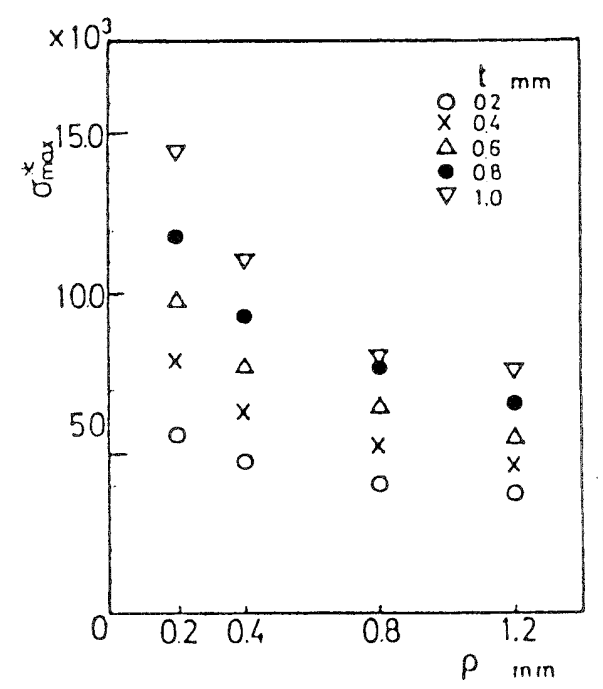

$\sigma_{\text {max }}^{*}:$ maximum stress at the notch bottom

Fig. 7 The relation among $\sigma^{*}{ }_{\max }, \rho$ and $t$ 




(a) in the case of $d=5.6 \mathrm{~mm}$

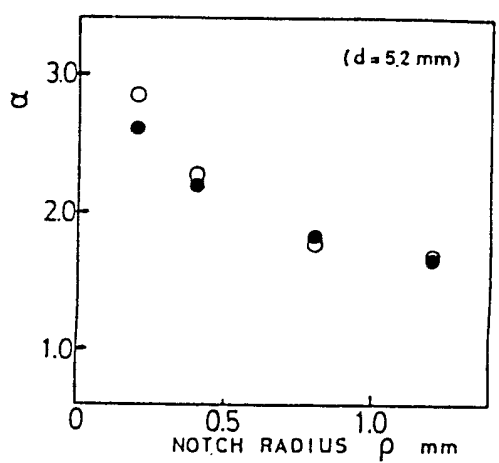

(b) in the case of $d=5.2 \mathrm{~mm}$



(c) in the case of $d=4.8 \mathrm{~mm}$

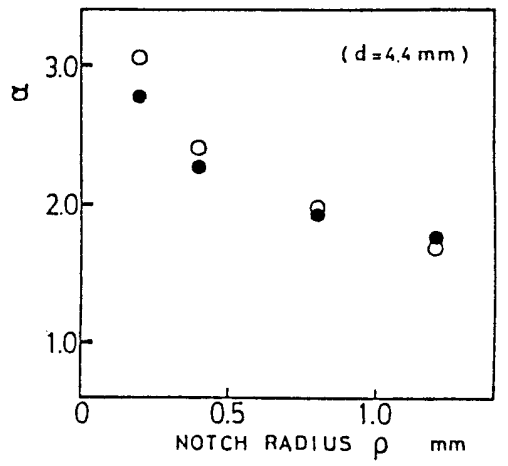

(d) in the cance of $d=4.4 \mathrm{~mm}$

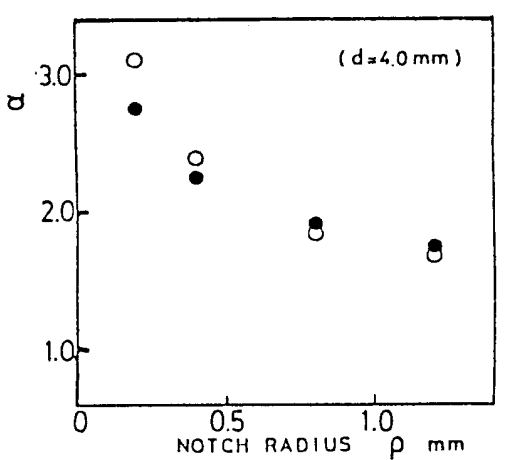

(e) in the case of $d=4.0 \mathrm{~mm}$

: $\alpha_{m}$ under ultrasonically vibrating stress

$0: \alpha$ under static load

$d:$ diameter of the notch bottom

Fig. 8 The relation between the stress concentration factor, $\alpha$, and notch radius, $\rho$

\section{2 Stress concentration factor under ultrasoni- cally vibrating stress}

Values $\alpha_{m}$ under ultrasonically vibrating stress obtained from Eq. (2) are shown in Figs. 8 (a) to (e). Further more, the value $\alpha$ in the static case obtained by the FEM is also plotted in the figures. The codition for $\alpha$ was that the large end surface of the horn was fixed, and a static tensile load of $100 \mathrm{~N}$ was applied to the free end of the testpiece. It is clear that $\alpha_{m}$ under ultrasonically vibrating stress agrees with $\alpha$ under a static load.

Figure 9 shows the relation of $d / D$ and $\rho / D$ to $\alpha_{m}$ under ultrasonically vibrating stress. These relationships show good agreement in accordance with the chart by Peterson ${ }^{(9)}$.

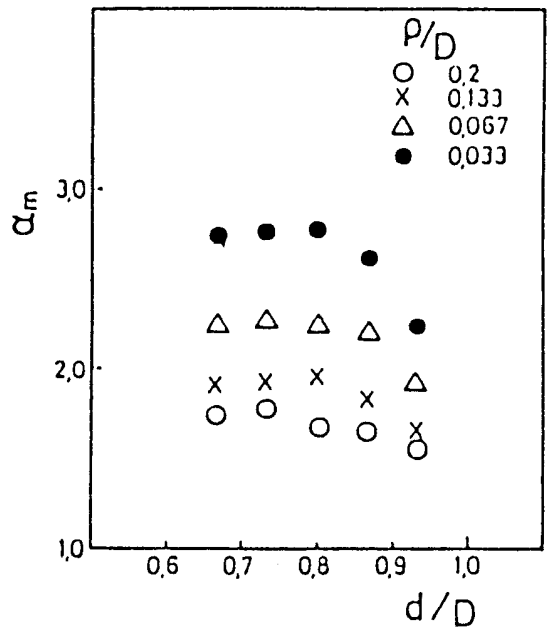

$\alpha_{m}$ : stress concentration factor under ultrasonically vibrating stress

$d:$ diameter of the notch bottom

$D$ : diameter of the plain testpiece $(D=6 \mathrm{~mm})$

Fig. 9 The relation between $\alpha_{m}$ and $d / D$ 


\section{Fatigue Strength Reduction Factor Under Ultrasonically Vibrating Stress}

\section{1 Calculation method for fatigue strength reduction factor}

In general, the fatigue strength reduction factor under push-pull alternating stresses of conventional repeating speed is obtained by ordinary fatigue tests. In the case of ultrasonic vibration, however, no fatigue limit of notched specimens has yet been obtained by ultrasonic fatigue tests because of the difficulty of direct stress measurement, though it is possible to measure the displacement amplitude of the free-end surface of the testpiece. Therefore, assuming that the allowable displacement amplitude corresponds to the fatigue limit of the testpiece and that the displacement amplitude of the free end surface of the testpiece obtained by eigenmode analysis corresponds to the mean stress of notch section, the fatigue limit, $\sigma$, could be obtained as follows.

$$
\left.B^{*} / \sigma_{\text {mean }}^{*}=B_{w} / \sigma_{w} \quad \therefore \sigma_{w}=\left(B_{w} / B^{*}\right) \cdot \sigma_{\text {mean }}^{*} \text { ( } 3\right)
$$

where

$B^{*}$ : Analyzed axial-direction displacement amplitude of the free-end surface of the testpiece under analysis.

$\sigma_{\text {mean }}^{*}$ : Mean stress of the notch section by analysis

$B_{w}$ : Allowable displacement amplitude in the ultrasonic fatigue test

$\sigma_{w}:$ Fatigue limit of the notched testpiece

By substituting the fatigue limit $\sigma_{w}$ obtained by the above equation into the following Eq. (4), the fatigue strength reduction factor $\beta_{m}$ under ultrasonically vibrating stress is obtained.

$$
\beta_{m}=\frac{\sigma_{w_{0}}}{\sigma_{w}}
$$

where $\sigma_{w_{0}}:$ Fatigue limit for plain specimen whose diameter is equal to the notch-root diameter.

\subsection{Ultrasonic fatigue test}

5.2.1 Test equipment and test method Figures 10 and 11 show the ultrasonic fatigue test equipment which consists of the external synchronization type CR oscillator ( 9 to $55 \mathrm{kHz}$ ), wide-band power amplifier $(2 \mathrm{~kW})$, controller, input A.C. voltmeter, Nickel-magnetostrictive type transducer $(17 \mathrm{kHz})$ and horn (titanium alloy; $17 \mathrm{kHz}$ ). The strain amplitude measuring equipment consists of the eddy current type displacement pickup, preamplifier, output digital voltmeter, synchroscope, and frequency counter. For the testpiece cooling, a freezer, tank and pump (labopump) are used. The V. C. I. (volatile corrosion inhibitor) aqueous solution kept at $5^{\circ} \mathrm{C}$ is used as cooling water ${ }^{(4)(8)}$. Through the use of the abovementioned equipment, the ultrasonic fatigue test is conducted to obtain the allowable displacement amplitude. The material of the testpiece is $\mathrm{S} 10 \mathrm{C}$ and its chemical composition is shown in Table 2. The plain testpiece having a diameter of $6 \mathrm{~mm}$ also undergoes a fatigue test.

5.2.2 Results of the fatigue tests Figure 12 shows the $S-N$ curve of a plain testpiece. The stress amplitude on the ordinate has been obtained from the value of the displacement amplitude at the free-end surface using the vertical vibration theory of the rod.

Figure 13 shows the relation between the displacement amplitude of the free-end surface and the num-

Table 2 Chemical composition of the testpiece

\begin{tabular}{|c|c|c|c|c|c|c|c|}
\hline $\mathrm{S} 10 C$ & $\mathrm{Si}$ & $\mathrm{Mn}_{\mathrm{n}}$ & $\mathrm{P}$ & $\mathrm{S}$ & $\mathrm{Cu}$ & $\mathrm{T}-\mathrm{Al}$ & $\mathrm{Ni}+\mathrm{Cr}$ \\
\hline 0.10 & 0.02 & 0.46 & 0.019 & 0.016 & 0.01 & 0.046 & 0.03 \\
\hline
\end{tabular}

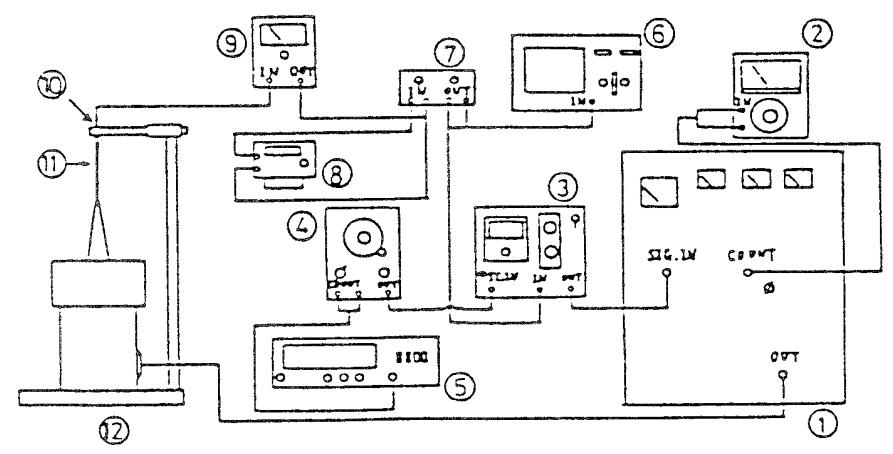

(1) Amplifier

(2) Input Volt meter

(3) Controller

(4) CR oscillater
(5) Frequency counter

(6) Synchroscope

(7) Pre-amplifier

(8) Digital Volt meter
(9) Gap sensor

(10) Pick up

(11) Specimen

(12) U.S. testing machine

Fig. 10 Equipment for ultrasonic fatigue tests

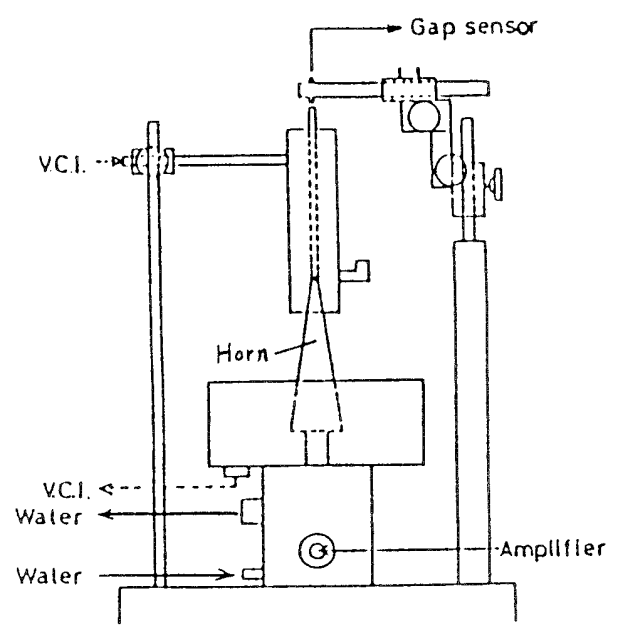

Fig. 11 Ultrasonic testing machine $(17 \mathrm{kHz})$ 
ber of cycles of stress. These $A-N$ curves correspond to the ordinary $S-N$ curves for the notch depth of 0.6 $\mathrm{mm}$, from which the values of the allowable displacement amplitude for various notch shapes are obtained. Figure 14 shows these values of allowable displacement amplitudes with various notch depths and notch radii.

\section{3 Fatigue strength reduction factor under ultrasonically Vibrating Stress}

Now, by substituting the value of $B_{w}, \sigma^{*}$ mean and $B^{*}$ into Eq. (3), the fatigue limit, $\sigma_{w}$, is obtained. Figure 15 shows the relation among $\sigma_{w}, \rho$ and $t$. Fatigue strength reduction factor under ultrasonically vibrating stress is obtained by Eq. (4). Figure 16 shows the relation between $\rho / D$ and $\beta_{m}$.

Figure 17 shows the relation between $\alpha_{m}$ and $\beta_{m}$ under ultrasonically vibrating stress. It shows a nearly linear relation between $\alpha_{m}$ and $\beta_{m}$.

The relation between the fatigue strength reduction factor and $d / D$ is shown in Figs. 18 (a) to (d).

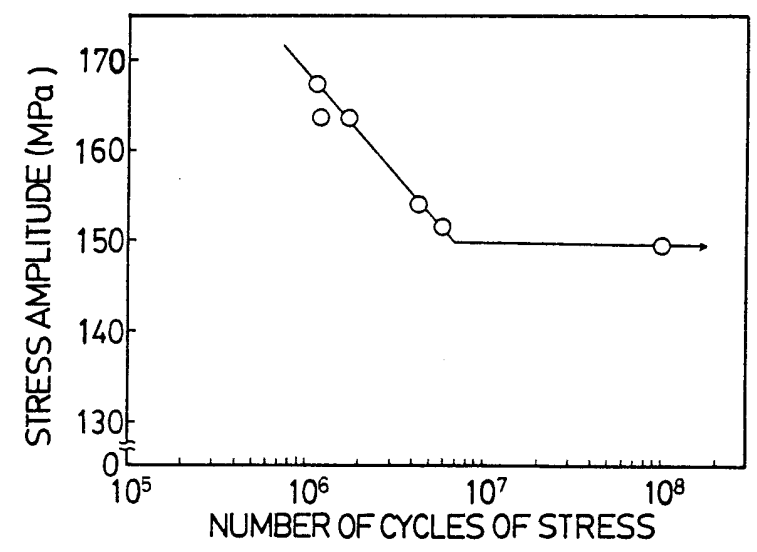

Fig. $12 S-N$ curve of a plain testpiece (diameter is 6 $\mathrm{mm})$

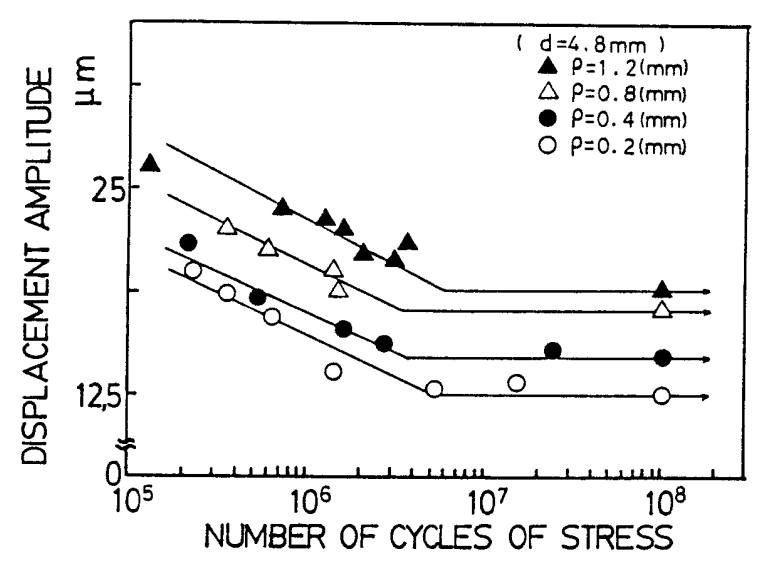

$A$ : displacement amplitude that is proportional to stress amplitude

Fig. $13 A-N$ curves of notched testpiece
Here $\beta_{0}$ is the ratio of the allowable displacement amplitude of the notched testpiece to the allowable displacement amplitude of the plain specimen, obtained by the result of the ultrasonic fatigue test.

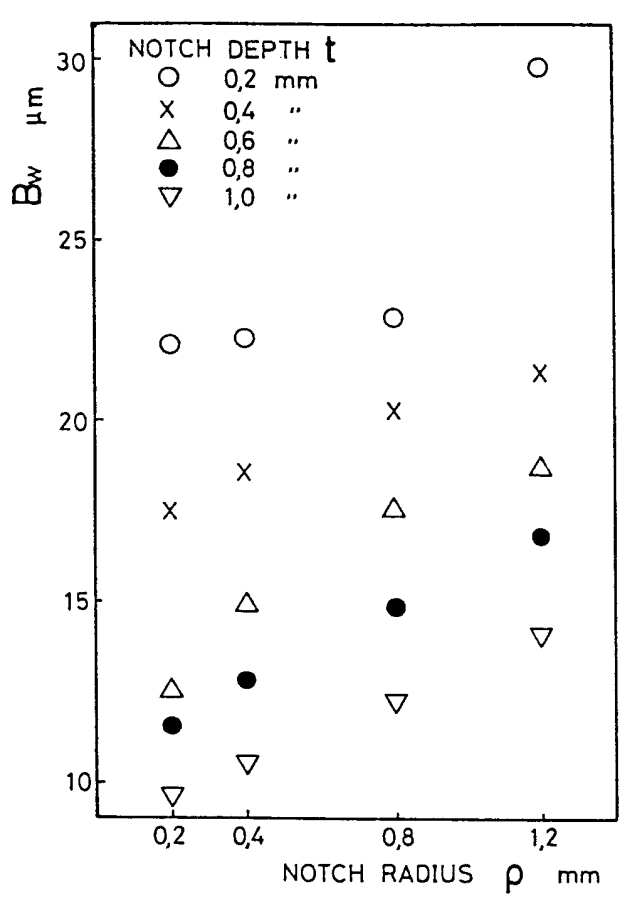

$B_{w}:$ allowable displacement amplitude $\rho:$ notch radius

$t:$ notch depth

Fig. 14 The relation among $B_{w}, \rho$ and $t$

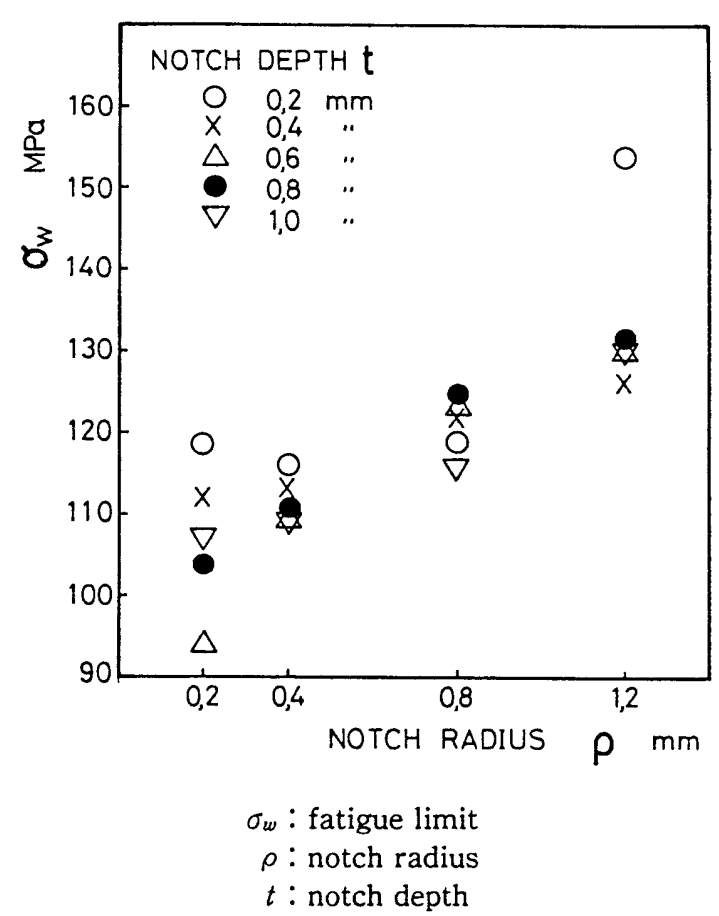

Fig. 15 The relation among $\sigma_{w}, \rho$ and $t$ 


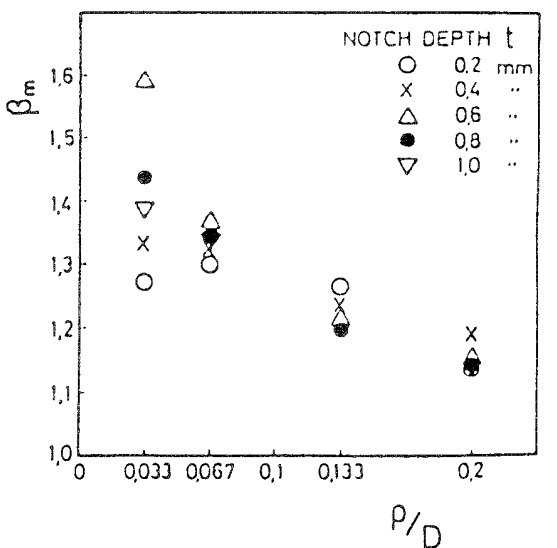

$\beta_{m}$ : fatigue strength reduction factor under ultrasonically vibrating stress

$\rho:$ notch radius

$D: 6 \mathrm{~mm}$

Fig. 16 The relation between $\beta_{m}$ and $\rho / D$

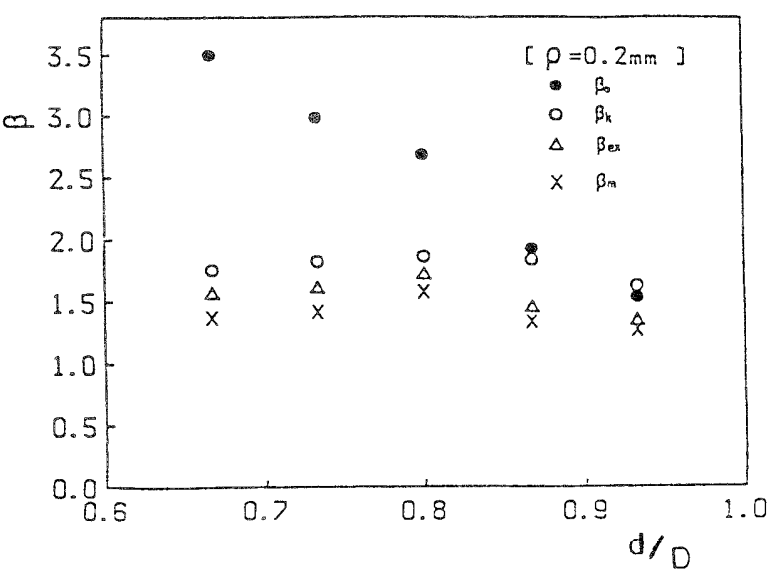

(a) in the case of $\rho=0.2 \mathrm{~mm}$

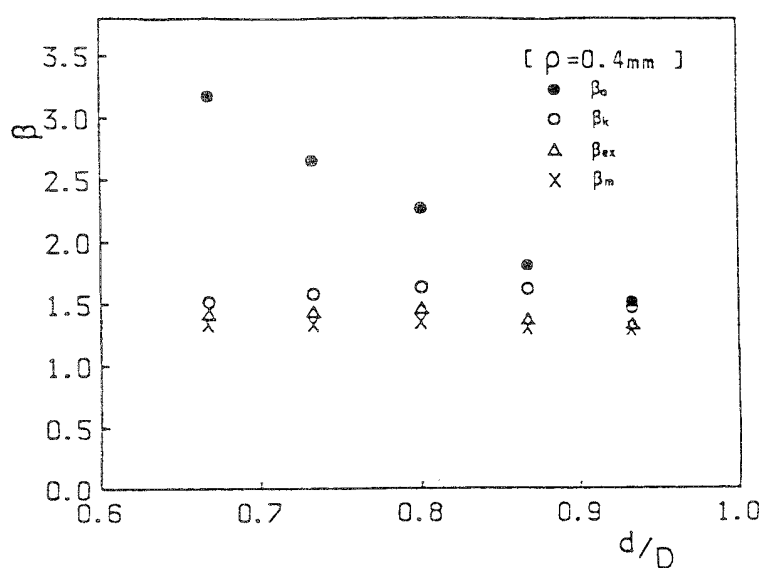

(b) in the case of $\rho=0.4 \mathrm{~mm}$

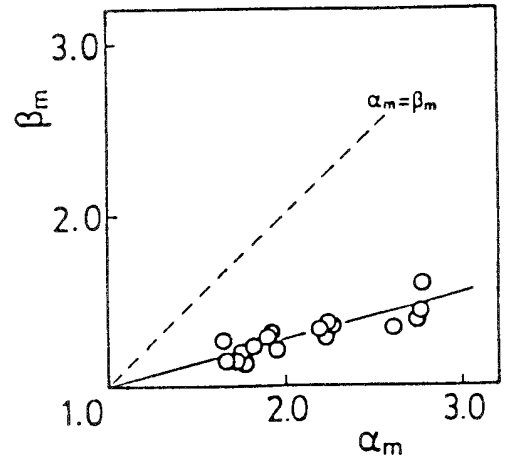

$\alpha_{m}$ : stress concentration factor under ultrasonically vibrating stress

$\beta_{m}$ : fatigue strength reduction factor under ultrasonically vibrating stress

Fig. 17 The relation between $\alpha_{m}$ and $\beta_{m}$

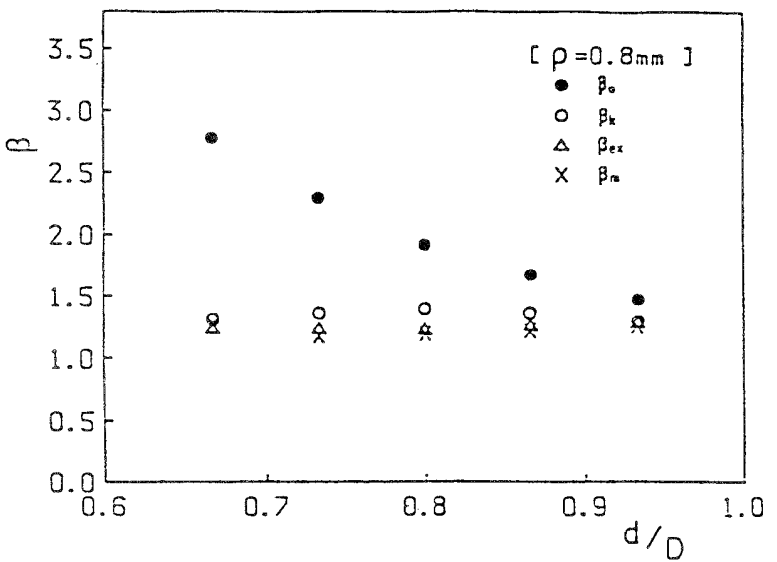

(c) in the case of $\rho=0.8 \mathrm{~mm}$

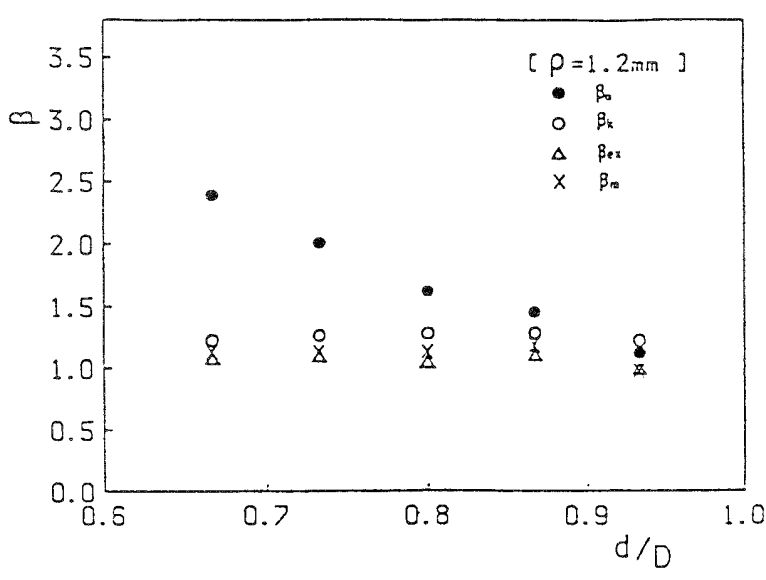

(d) in the case of $\rho=1.2 \mathrm{~mm}$

: the ratio of allowable displacement amplitudes, $\beta_{0}$, obtained by Eq. ( 5 )

$O: \beta_{k}$ under conventional repeating speed

$\triangle: \beta_{e x}=\beta_{o} \times d^{2} / D^{2}$

$x: \beta_{m}$ under ultrasonically vibrating stress

Fig. 18 The relation between the fatigue strength reduction factor, $\beta$, and $d / D$ 
Namely,

$$
\beta_{0}=B_{o} / B_{a}
$$

where

$B_{a}$ : Allowable displacement amplitude of notched testpiece

$B_{b}$ : Allowable displacement amplitude of plain testpiece

Further, $\beta_{k}$ in Figs. 18 (a) to (d) has been calculated from the following equation $(6)^{(10)}$ which applies to the case of push-pull alternating stresses at a conventional repeated speed for the circular Vgrooved round bar recommended by the Japan Society of Mechanical Engineers :

$$
\beta_{k}=1+\xi_{1} \xi_{2} \xi_{3} \xi_{4} \xi_{5}
$$

Figure 18 indicates that there is a similar tendency between $\beta_{m}$ under ultrasonically vibrating stress and $\beta_{k}$ under push-pull alternating stresses at ordinary repeated speed, but $\beta_{m}$ generally tends to become smaller than $\beta_{k}$.

Figure 19 shows the relation between $\rho / d$ and $\beta$. It indicates that as $\rho / d$ becomes smaller, $\beta_{m}$ under ultrasonically vibrating stress gradually becomes larger.

\section{Discussion}

6.1 Method of experimentally obtaining the fatigue strength reduction factor in ultrasonic fatigue tests

The value $\beta_{0}$ shown in Figs. 18 (a) to (d) is the ratio between the allowable displacement amplitude of the plain testpiece and that of the notched testpiece obtained in the ultrasonic fatigue test. In all of the graphs $\beta_{0}$ is larger than $\beta_{m}$ under ultrasonically vibrating stress, and this difference becomes large as the notch depth increases. The reason for this seems to be that no effects of the area of the cross section are

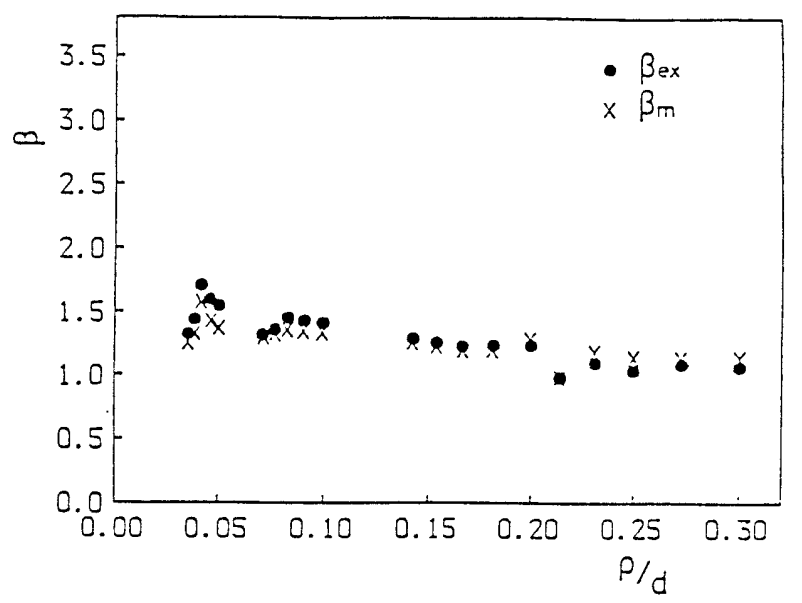

$: \beta_{e x}=\beta_{0} \times d^{2} / D^{2}$

$\times: \beta_{m}$ under ultrasonically vibrating stress

Fig. 19 The relation between $\beta$ and $\rho / d$ considered in $\beta_{0}$. Namely, since sudden changes in stress occur at the notch, the plain testpiece and notched testpiece give different nominal stress values, even if the displacement amplitudes at the free-end surfaces of the test pieces are the same. Therefore, when the $\mathrm{V}$-groove is replaced with a square groove with the same area of the notch section as shown in Fig. 20, we can take the effect of nominal stress into consideration. Namely, when the fatigue strength reduction factor taking an area of the notch section into consideration is denoted by $\beta_{e x}$, it can be defined by the following equation:

$$
\beta_{e x}=\beta_{0} \cdot \frac{d^{2}}{D^{2}}
$$

The $\beta_{e x}$ value thus obtained shows good agreement with $\beta_{m}$ as shown in Fig. 18 (a) to (d) and Fig. 19. Namely, in the case of the circular V-groove, it is possible to estimate the fatigue strength reduction factor $\beta_{e x}$ under ultrasonically vibrating stress. Further, the six kinds of notches shown by " $X$ " marks in Table 3, out of the 20 kinds of notches, are roundgrooved ones. In the case of the materials of the roundgrooved notches, the values of $\beta_{e x}$ and $\beta_{0}$ also show good agreement and in the case of the circular roundgrooves, it is similarly possible to estimate the fatigue strength reduction factor under ultrasonically vibrat. ing stress.

6.2 Frequency effect upon fatigue limits of notched and plain testpieces

The value $\beta_{m}$ under ultrasonically vibrating stress obtained in this study shows agreement with $\beta_{k}$ at

Table $3 \quad \mathrm{~V}$-grooves and round-grooves

$\mathrm{O}: \mathrm{V}$-groove

$x$ : round-groove (without notch angle)

$d$ : diameter of notch bottom

$\rho:$ notch radius


Fig. 20 Round bar with a circular V-groove and with a square groove 
normal repeated speed which has been obtained from Eq. (6) stipulated by the Japan Society of Mechanical Engineers. This seems to indicate that the frequency effect on the fatigue limits are substantially equal for the notched and plain testpieces. However, $\beta_{m}$ generally shows a slightly lower value. This may be due to the fact that the rate of increase in the fatigue limit due to the frequency effect in the notched testpiece is slightly larger than in the plain one.

\section{Conclusions}

To clarify the notch effect under ultrasonically vibrating stress, an eigenmode analysis of the ultrasonic vibration system containing a round bar of mild steel with a circular $\mathrm{V}$-groove and an ultrasonic fatigue test of the same testpiece were conducted. As a result, the values of the stress concentration factor and fatigue strength reduction factor under ultrasonically vibrating stress were obtained in the case of round bar of mild steel with the circular Vgroove and the following two points have been clarified :

(1) The value of the shape coefficient $\alpha_{m}$ under ultrasonically vibrating stress is nearly equal to the value under the static load.

(2) The value of fatigue strength reduction factor $\beta_{m}$ under ultrasonically vibrating stress substantially agrees with $\beta_{k}$ at a conventional repeated speed that is recommended by the Japan Society of Mechanical Engineers. Further, the value of $\beta_{m}$ sub. stantially agrees with the value of $\beta_{e x}$ which has been obtained by Eq. ( 7 ).

In the future, the authors intend to carry out eigenmode analyses and ultrasonic fatigue tests on various kinds of materials and notch shapes to further clarify the notch effect under ultrasonically vibrating stress.

\section{References}

(1) Koganei, H., Tanaka, T. and Sakurai, T., Material (in Japanese), Vol. 24, No. 263 (1975-8), p. 45.

(2) Awatani, J., Trans. Jpn. Soc. Mech. Eng., (in Japanese), Vol. 40, No. 337 (1974-9), p. 2453.

(3) Mason, W. P. and MacDonald, D. E., J. Acoust. Soc. Am., 51 (1972), p. 894.

(4) Kikukawa, M., Oji, S. and Ogura, K., Trans. Jpn. Soc. Mech. Eng., (in Japanese), Vol. 32, No. 235 (1966-3), p. 363.

(5) Udoguchi, T., Kato,N. and Yamane, M., Jour., Jpn. Soc. Mech. Eng., (in Japanese), Vol. 68, No. 552 (1965), p. 17.

(6) Yamane, M., Trans. Jpn. Soc. Mech. Eng., (in Japanese), Vol. 28, No. 191 (1962), p. 893.

(7) Ono, T. and Kaga, Y., Prepr. of Jpn. Soc. Mech. Eng., (in Japanese), No. 720-1 (1972-4), p. 97.

(8) Terao, K., Kuno, T. and Mizuno, M., Bull. JSME, Vol. 24, No. 196 (1981-10), p. 1708.

(9) Peterson, R.E., Stress Concentration Factors, (1974), p. 50, A Wiley-Interscience Publication.

(10) The Japan Society of Mechanical Engineers, Kinzoku Zairyo-Tsukare Tsuyosa no Sekkei Shiryo I, (in Japanese), (1961), p. 114., JSME. 